\title{
Bilateral sixth cranial nerve palsy after unintentional dural puncture
}

\author{
[Paralysie bilatérale du sixième nerf crânien à la suite d'une brèche durale \\ accidentelle]
}

Geneviève Arcand MD, ${ }^{*}$ François Girard MD FRCPC, ${ }^{*}$ Michael McCormack MD FRCSC, $\dagger$ Philippe Chouinard MD FRCPC, ${ }^{*}$ Daniel Boudreault MD FRCPC, ${ }^{*}$ Stephan Williams MD PhD*

\begin{abstract}
Purpose: Bilateral sixth nerve palsy is a known though uncommon complication following dural puncture. The recommended treatment consists of hydration and alternate monocular occlusion. The value and the timing of an epidural blood patch (EBP) for sixth nerve palsy remains controversial as some authors have demonstrated benefits in performing an EBP early in course of the nerve palsy whereas others have not found any advantage when an EBP was performed later.
\end{abstract}

Clinical features: A 40-yr-old woman developed bilateral sixth nerve palsy ten days after an unintentional dural puncture. An EBP was done within $24 \mathrm{hr}$ after the onset of the symptoms and immediate improvement of the diplopia was noted by the patient and confirmed by an ophthalmologist. Complete resolution of the diplopia occurred 36 days after the dural puncture.

Conclusion: Blood patching within $24 \mathrm{hr}$ of the onset of diplopia may be a reasonable treatment for ocular nerve palsy as it relieved the postdural puncture headache and produced partial improvement of the diplopia.

Objectif : La paralysie bilatérale du sixième nerf crânien (abducens) est une complication connue, mais rare, de la ponction durale. Le traitement recommandé consiste en l'hydratation et l'occlusion monoculaire alternée. La valeur d'un colmatage sanguin péridural (CSP), en cas de paralysie du nerf abducens, et le moment choisi pour le réaliser, demeurent controversés, car certains auteurs ont démontré les avantages d'un CSP précoce au cours de la paralysie alors que d'autres n'ont trouvé aucun avantage à un CSP plus tardif.

Éléments cliniques : Une paralysie bilatérale du nerf abducens s'est développée chez une femme de 40 ans, dix jours après une brèche durale accidentelle. Un CSP a été fait dans les 24 h suivant l'apparition des symptômes et une amélioration immédiate de la diplopie a été constatée par la patiente et confirmée par un ophtal- mologiste. La résolution complète de la diplopie est survenue 36 jours après la ponction durale.

Conclusion : Le colmatage sanguin péridural réalisé dans les $24 \mathrm{~h}$ qui suivent l'apparition d'une diplopie constitue un traitement raisonnable de la paralysie du nerf abducens, puisqu'il soulage la céphalée post-ponction durale et réduit partiellement la diplopie.

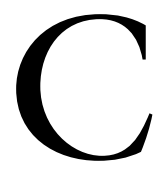

RANIAL nerve palsy (CNP) is a rare complication following dural puncture. The sixth cranial (abducens) nerve is the most commonly affected nerve. We report a case of bilateral sixth nerve palsy after unintentional dural puncture that improved immediately after an epidural blood patch (EBP).

\section{Case report}

A 40-yr-old woman was referred to our institution for surgical management of a neurogenic bladder. Her past medical history included chronic renal insufficiency requiring hemodialysis. On the day of the surgery, the risks and benefits of an epidural for postoperative pain relief were discussed and the patient gave informed consent.

After skin preparation and local anesthesia at the T11 to T12 interspace, the epidural space was identified on the first attempt with a 17-gauge (g) Tuohy needle (Braun Medical Inc., Bethlehem, PA, USA) using the loss of resistance to air technique. No cerebrospinal fluid (CSF) or blood return was noted. An epidural catheter $\left(20 \mathrm{~g}\right.$; Portex ${ }^{\circledR}$ Nylon, Keene, $\mathrm{NH}$,

From the Departments of Anesthesiology, ${ }^{*}$ and Surgery, $†$ CHUM, Notre-Dame Hospital, Montréal, Québec, Canada.

Address correspondence to: Dr. François Girard, Department of Anesthesiology, CHUM, Hôpital Notre-Dame, 1560 Sherbrooke East,

Montréal, Québec H2L 4M1, Canada. Phone: 514-890-8000, ext. 26876; Fax: 514-412-7653;

E-mail: francois.girard.chum@ssss.gouv.qc.ca

Accepted for publication October 3, 2003.

Revision accepted March 22, 2004. 
USA) was inserted. Clear liquid was then aspirated from the catheter raising the concern of a dural breach. The catheter was withdrawn and resited uneventfully at the T12 to Ll level using the same technique. Aspiration and test dose were negative for intravascular or intrathecal catheter placement. General anesthesia was induced with iv fentanyl 200 $\mu \mathrm{g}$, propofol $130 \mathrm{mg}$, and rocuronium $40 \mathrm{mg}$. Sevoflurane at 0.8 minimum alveolar concentration was used for maintenance of anesthesia. An epidural infusion of bupivacaine $0.0625 \%$ and fentanyl 2 $\mu \mathrm{g} \cdot \mathrm{mL}^{-1}$ at $10 \mathrm{~mL} \cdot \mathrm{hr}^{-1}$ was used for intraoperative analgesia. No other narcotics were given. The surgery lasted four hours.

In the recovery room, the patient had a sensory block up to the T5 dermatome bilaterally and no evidence of motor block. The patient had an uneventful recovery and did not complain of any pain. The following day, the patient reported abdominal pain. A clear discharge was noted at the epidural insertion site. Because of the doubt about the nature of the discharge (local anesthetic vs CSF) and the inadequacy of pain relief, epidural analgesia was discontinued. Patient-controlled analgesia with iv hydromorphone was initiated and good pain control was achieved.

Five days later, the patient complained of a mild frontal headache, a sensation of traction in the eyes, and nausea that eventually decreased in intensity over the following days. Her headache worsened with assumption of the upright position and improved with adoption of the supine position. On the tenth postoperative day, the patient suddenly complained of diplopia. Neurological and ophthalmological consultations were sought by the surgical team and revealed bilateral abducens nerve palsy. The cerebral computed tomogram (CT) was normal. The anesthesiologist was then called to evaluate the patient. The diagnosis of postdural puncture headache $(\mathrm{PDPH})$ with secondary sixth CNP was made.

An EBP was performed on the same day. With the patient lying in the lateral decubitus position, $20 \mathrm{~mL}$ of autologous blood was injected into the epidural space at the Tll to Tl2 level. An immediate improvement of the diplopia was noted by the patient and confirmed by the ophthalmologist. The patient remained supine for one hour and complete relief of the headache was noted two hours after the procedure without any other therapeutic intervention. The patient was discharged from the hospital on the $13^{\text {th }}$ day after surgery. Complete resolution of the diplopia occurred 36 days after the dural puncture.

\section{Discussion}

CNP is an unusual complication of dural puncture. The reported incidence after spinal anesthesia varies from $1: 300$ to $1: 8000 .{ }^{1}$ Vandam et al. reported an incidence of $1: 140$ in patients with established PDPH from dural puncture with 16-g needles. ${ }^{2}$ All cranial nerves can be involved with the exception of cranial nerves I, IX, and X. The sixth cranial nerve is the most frequently affected because of its long intracranial course. ${ }^{2,3} \mathrm{CNP}$ after dural puncture is attributed to continuous CSF leakage through the dural hole. ${ }^{4}$ Magnetic resonance imaging has demonstrated that this results in intracranial hypotension with descent of the brain, even in the supine position, causing traction of the sixth nerve and pain-sensitive structures. ${ }^{4}$ The stretching of the nerve is thought to cause local ischemia and nerve dysfunction. ${ }^{5}$ This can be seen in association with other signs of intracranial hypotension such as vertigo, nausea, and vomiting.

Postdural puncture CNP is a diagnosis of exclusion. Other etiologies need to be considered, including multiple sclerosis, myasthenia gravis, thyroid disease, diabetes, myositis, intracranial tumour, arteriovenous malformation, and hematoma. ${ }^{6}$ The patient did not present with any of those diseases, and evaluations by a neurologist and an ophthalmologist as well as cerebral CT confirmed postdural puncture $\mathrm{CNP}$ as the most likely diagnosis.

The largest compilation of cases of diplopia after spinal anesthesia showed that the development of CNP was rare prior to the fourth day after dural puncture and the mean presentation time was ten days after dural puncture. ${ }^{7}$ Although two-thirds of patients showed complete resolution within a week after the diagnosis, $25 \%$ remained symptomatic for more than a month. In $10 \%$ of the cases, CNP persisted for more than three months. ${ }^{8}{ }^{8}$ In previous reports, EBP performed more than $24 \mathrm{hr}$ after the onset of symptoms did not restore cranial nerve function even with complete resolution of the headache. ${ }^{10-12}$ In contrast to these previous reports, our case is interesting as the patient demonstrated immediate, albeit partial, improvement of the diplopia following the EBP, which was administered within $24 \mathrm{hr}$ of the onset of symptoms of CNP. In their report, Dunbar et al. also hypothesized that early blood patch could have changed the course of sixth nerve palsy after dural puncture. ${ }^{13}$ Prolonged downward displacement and stretching of the abducens nerve may be more likely to result in a persistent palsy as is the case in peripheral nerve palsies due to prolonged compression. If this is the case, then early treatment of CNP with an EBP may be more successful than delayed blood patching. 
In conclusion, we present a case of bilateral sixth nerve palsy that improved immediately after an EBP done within $24 \mathrm{hr}$ of the onset of the ocular symptoms. Blood patching within $24 \mathrm{hr}$ of the onset of diplopia may be a reasonable treatment for ocular nerve palsy as it relieved the PDPH and produced partial improvement of the diplopia.

\section{References}

1 Greene NM. Neurological sequelae of spinal anesthesia. Anesthesiology 1961; 22: 682-98.

2 Vandam LD, Dripps RD. Long-term follow-up of patients who received 10,098 spinal anesthetics. Syndrome of decreased intracranial pressure (headache and ocular and auditory difficulties). JAMA 1956; 161: 586-91.

3 Thömke F, Mika-Grïttner A, Visbeck A, Brïhl K. The risk of abducens palsy after diagnostic lumbar puncture. Neurology 2000; 54: 768.

4 Pannullo SC, Reich JB, Krol G, Deck MD, Posner JB. MRI changes in intracranial hypotension. Neurology 1993; 43: 919-26.

5 Barsoum WK, Mayerson J, Bell GR. Cranial nerve palsy as a complication of operative traction. Spine $1999 ; 24$ : 585-6.

6 Vial F, Bouaziz H, Adam A, Buisset L, Laxenaire MC, Battaglia $A$. Sixth cranial nerve palsey and spinal anaesthesia (French). Ann Fr Anesth Réanim 2000; 20: 32-5.

7 Thorsen G. Neurological complications after spinal anaesthesia and results from 2493 follow-up cases. Acta Chir Scand Suppl 1947; 121: 1-272.

8 De Veuster I, Smet H, Vercauteren M, Tassignon MJ. The time course of a sixth nerve paresis following epidural anesthesia. Bull Soc Belg Ophtalmol 1994; 252: 45-7.

9 Duffy PJ, Crosby ET. The epidural blood patch. Resolving the controversies. Can J Anesth 1999; 46: 878-86.

10 Heyman HJ, Salem MR, Klimov I. Persistent sixth cranial nerve paresis following blood patch for postdural puncture headache. Anesth Analg 1982; 61: 948-9.

11 Szokol JW, Falleroni MJ. Lack of efficacy of an epidural blood patch in treating abducens nerve palsy after unintentional dura puncture. Reg Anesth Pain Med 1999; 24: 470-2.

12 Follens I, Godts D, Evens PA, Tassignon MJ. Combined fourth and sixth cranial nerve palsy after lumbar puncture: a rare complication. A case report. Bull Soc Belge Ophtalmol 2001; 281: 29-33.

13 Dunbar $S A$, Katz NP. Failure of delayed epidural blood patching to correct persistent cranial nerve palsies. Anesth Analg 1994; 79: 806-7.

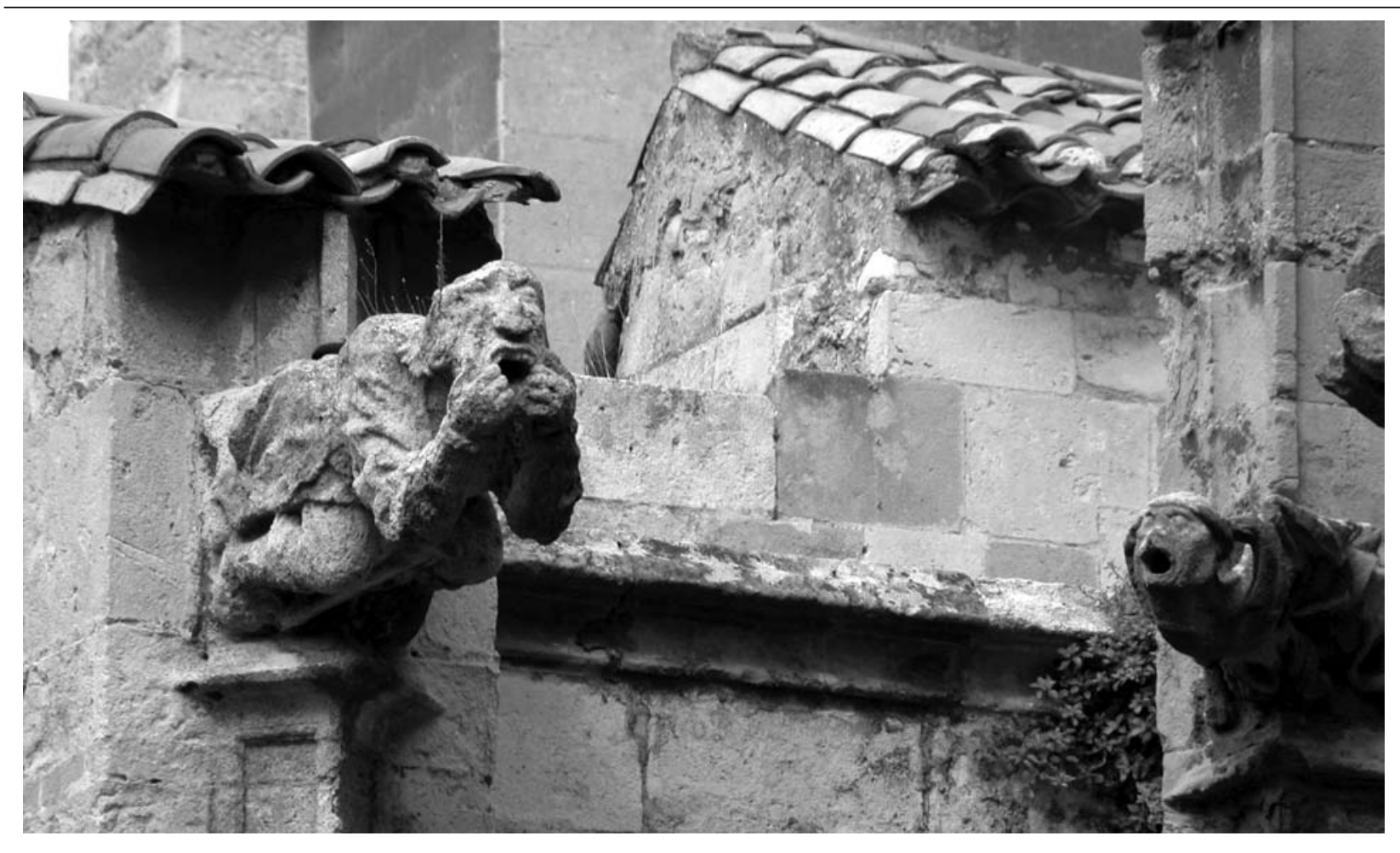

Narbonne - France 